\title{
Zoledronic acid suppresses transforming growth factor- $\beta$-induced fibrogenesis by human gingival fibroblasts
}

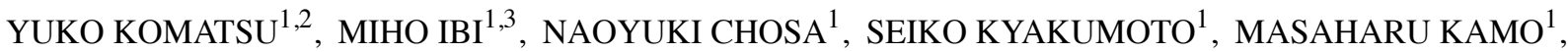 \\ TOSHIYUKI SHIBATA ${ }^{4}$, YOSHIKI SUGIYAMA ${ }^{2}$ and AKIRA ISHISAKI ${ }^{1}$ \\ ${ }^{1}$ Division of Cellular Biosignal Sciences, Department of Biochemistry, Iwate Medical University, Iwate 028-3694; \\ ${ }^{2}$ Division of Oral and Maxillofacial Surgery, Department of Reconstructive Oral and Maxillofacial Surgery, \\ Iwate Medical University, Iwate 020-8505; ${ }^{3}$ Department of Molecular and Cellular Pharmacology, Iwate Medical University \\ School of Pharmaceutical Sciences, Iwate 028-3694; ${ }^{4}$ Department of Oral and Maxillofacial Surgery, \\ Gifu University Graduate School of Medicine, Gifu 501-1194, Japan
}

Received October 13, 2015; Accepted April 11, 2016

DOI: 10.3892/ijmm.2016.2582

\begin{abstract}
Bisphosphonates (BPs) are analogues of pyrophosphate that are known to prevent bone resorption by inhibiting osteoclast activity. Nitrogen-containing BPs, such as zoledronic acid (ZA), are widely used in the treatment of osteoporosis and bone metastasis. However, despite having benefits, ZA has been reported to induce BP-related osteonecrosis of the jaw (BRONJ) in cancer patients. The molecular pathological mechanisms responsible for the development of BRONJ, including necrotic bone exposure after tooth extraction, remain to be elucidated. In this study, we examined the effects of ZA on the transforming growth factor- $\beta$ (TGF- $\beta$ )induced myofibroblast (MF) differentiation of human gingival fibroblasts (hGFs) and the migratory activity of hGFs, which
\end{abstract}

Correspondence to: Professor Akira Ishisaki, Division of Cellular Biosignal Sciences, Department of Biochemistry, Iwate Medical University, 2-1-1 Nishitokuta, Yahaba-cho, Shiwa-gun, Iwate 028-3694, Japan

E-mail: aishisa@iwate-med.ac.jp

Abbreviations: BPs, bisphosphonates; ZA, zoledronic acid; BRONJ, BPs-related osteonecrosis of the jaw; ECs, epithelial cells; GFs, gingival fibroblasts; hGFs, human GFs; TGF- $\beta$, transforming growth factor- $\beta$; BMP, bone morphogenetic protein; GDF, growth and differentiation factor; MIS, Mullerian inhibiting substance; R-Smads, receptor-regulated Smads; Co-Smad, common mediator Smad; I-Smads, inhibitory Smads; MFs, myofibroblasts; $\alpha$-SMA, $\alpha$-smooth muscle actin; MAPKs, mitogen-activated protein kinases; ERK, extracellular signal-regulated kinase; Cmax, maximum concentration in serum; FBS, fetal bovine serum; PBS, phosphate-buffered saline; GAPDH, glyceraldehyde 3-phosphate dehydrogenase; SDS-PAGE, SDS-polyacrylamide gel electrophoresis; JNK, c-Jun N-terminal kinase; EMT, epithelial-to-mesenchymal transition; GEF, guanine nucleotide exchange factor

Key words: zoledronic acid, human gingival fibroblasts, transforming growth factor- $\beta$, myofibroblast differentiation, migratory activity are important for wound closure by fibrous tissue formation. The ZA maximum concentration in serum (Cmax) was found to be approximately $1.47 \mu \mathrm{M}$, which clinically, is found after the intravenous administration of $4 \mathrm{mg} \mathrm{ZA}$, and ZA at this dose is considered appropriate for the treatment of cancer bone metastasis or bone diseases, such as Erdheim-Chester disease. At Cmax, ZA significantly suppressed i) the TGF- $\beta$-induced promotion of cell viability, ii) the TGF- $\beta$-induced expression of MF markers such as $\alpha$-smooth muscle actin ( $\alpha$-SMA) and type I collagen, iii) the TGF- $\beta$-induced migratory activity of hGFs and iv) the expression level of TGF- $\beta$ type I receptor on the surfaces of hGFs, as well as the TGF- $\beta$-induced phosphorylation of Smad2/3. Thus, ZA suppresses TGF- $\beta$-induced fibrous tissue formation by hGFs, possibly through the inhibition of Smad-dependent signal transduction. Our findings partly elucidate the molecular mechanisms underlying BRONJ and may prove to be beneficial to the identification of drug targets for the treatment of this symptom at the molecular level.

\section{Introduction}

Bisphosphonates (BPs) are analogues of pyrophosphate that are known to prevent bone resorption by inhibiting osteoclast activity (reviewed in ref. 1). BPs are used for the treatment of various bone diseases, including osteoporosis and bone metastasis in cancer with or without hypercalcemia (2). Nitrogen-containing BPs, such as zoledronic acid (ZA), are used in the treatment of osteoporosis and bone metastasis (reviewed in ref. 3), as well as in the treatment of other bone diseases, such as Erdheim-Chester disease (4). In addition, they are more potent inhibitors of bone resorption than non-nitrogen-containing BPs (reviewed in ref. 5). However, despite their several benefits, $\mathrm{ZA}$ induces BP-related osteonecrosis of the jaw (BRONJ) in cancer patients $(6,7)$. BRONJ is defined as necrotic bone exposure in the oral cavity continuing for $>8$ weeks in BP-treated patients who have not had received head and neck radiation therapy (8). The molecular mechanisms responsible for the development of BRONJ remain to be elucidated; however, some risk factors, including periodontitis with bacterial plaque in the oral cavity 
have been associated with this symptom (reviewed in ref. 7). Previous studies have suggested that infectious agents, including Actinomyces, play important roles in the etiology and progression of BRONJ (9-11). Interestingly, Kobayashi et al reported that ZA promoted the adherence of Streptococcus mutans to hydroxyapatite and the proliferation of oral bacteria obtained from healthy individuals, suggesting that ZA increases bacterial infection (12). Wound closure by oral epithelial cells (ECs) and gingival fibroblasts (GFs) is important, not only for successful wound healing, but also for the protection of the socket from oral bacterial infection following tooth extraction. Thus, it is possible that an oral bacterial infection may induce BRONJ in cooperation with other risk factors, such as diabetes mellitus with steroid intake (13) or with microvascular disease (14), smoking, prosthetic trauma, and implant treatment (15). In addition, the ability of GFs to migrate and synthesize type I collagen is essential for the formation of rigid gingival connective tissue to cover the intraoral bone exposure, which protects the alveolar bone of the maxilla and the jaw from infection with oral bacteria. However, the mechanisms through which ZA affects the ability of human GFs (hGFs) to migrate and synthesize the connective tissue at the molecular level remain to be elucidated.

When tissue injury occurs, the blood coagulation cascade is initiated, resulting in the formation of fibrous connective tissue, which functions as a scaffold for the influx of inflammatory cells. Platelets also aggregate at the site of injury, and become activated by binding to the negatively charged extravascular fibrous tissue, and release various growth factors, including transforming growth factor- $\beta$ (TGF- $\beta$ ) (reviewed in ref. 16). TGF- $\beta 1$ is known to be expressed in serveral types of cells, including hGFs, and is involved in the proliferation and differentiation of these cells $(17,18)$. Thus, the functions of TGF- $\beta$ seem to be autocrine or paracrine as regards the regulation of hGFs during oral inflammation and the wound healing processes at the site of injury. The TGF- $\beta$ superfamily consists of two families: the TGF- $\beta$ /activin/Nodal family and the bone morphogenetic protein (BMP)/growth and differentiation factor (GDF)/Mullerian inhibiting substance (MIS) family (reviewed in ref. 19).

The TGF- $\beta$ superfamily ligands initiate a cascade of signaling events by binding to their respective type I and type II receptors in the extracellular space. Following this, two type I and two type II receptors form a tetrameric complex. In this ligand-bound complex of type I and type II receptors, the type II receptor kinase activates the type I receptor kinase. The type I receptor induces intracellular signal transduction by phosphorylating the receptor-regulated Smads (R-Smads) (reviewed in refs. 20-23). Smads are central signal transducers of TGF- $\beta$ superfamily and are composed of 3 groups. The first group comprises the R-Smads; Smad1, Smad5 and Smad8 are primarily activated by the BMP-specific type I receptors, whereas Smad 2 and Smad3 are activated by TGF- $\beta$-specific type I receptors. The second group contains the common mediator Smad (Co-Smad; e.g., Smad4). The third group comprises the inhibitory Smads (I-Smads; e.g., Smad6 and Smad7). Activated R-Smads form complexes with the Co-Smad, which enter the nucleus, and, together with other cooperative proteins, positively or negatively control the transcription of specific target genes. I-Smads suppress the activation of R-Smads by competing with R-Smads for type I receptor interaction and by recruiting specific ubiquitin ligases, resulting in their proteasomal degradation (reviewed in ref. 24).

TGF- $\beta$ has the ability to induce the differentiation of various types of cells into myofibroblasts (MFs), which typically exhibit the formation of F-actin stress fibers (reviewed in ref. 25). We have previously demonstrated that TGF- $\beta$ induces the expression of the MF markers, $\alpha$-smooth muscle actin ( $\alpha$-SMA) and type I collagen, in fibroblastic cells derived from periodontal ligament (26). Sobral et al reported that TGF- $\beta$ induced the differentiation of hGFs into MFs in a Smad-dependent manner (27). Thus, TGF- $\beta$ is now known to induce MF differentiation from fibroblasts, which preferentially form a fibrous tissue. TGF- $\beta$ is also known to induce migratory activity in various types of cells, including fibroblastic cells in a Smaddependent manner (28-30). In addition, Bakin et al reported that TGF- $\beta$ regulates the migratory activity of ECs in a p38 mitogenactivated protein kinase (MAPK)-dependent manner (31), suggesting that TGF- $\beta$ induces cell migratory activity through MAPKs as opposed to Smads. Moreover, TGF- $\beta$ plays important roles in physiological wound closure by promoting cell migration and type I collagen synthesis. On the other hand, the abnormal and persistent appearance of MFs causes scar formation or fibrosis $(32,33)$. The abnormal potentiation of TGF- $\beta$ signaling in MFs possibly causes fibrogenic diseases. Therefore, MFs represent key players in the physiological reconstruction of connective tissue following injury and in generating the pathological tissue deformations that characterize fibrosis (34).

In this study, we investigated the mechanisms through which ZA, at its maximum concentration in serum (Cmax), which clinically, is usually found after the intravenous administration of $4 \mathrm{mg} \mathrm{ZA}$, which is the appropriate amount for the usual treatment of bone metastasis $(35,36)$ or bone diseases such as Erdheim-Chester disease (4), affects TGF- $\beta$-induced intracellular signal transduction and MF differentiation of hGFs, which are important processes for the progression of fibrogenesis during inflammation.

\section{Materials and methods}

Reagents. Recombinant TGF- $\beta$ was purchased from Peprotech, Inc. (Rocky Hill, NJ, USA). The TGF- $\beta$ type I receptor inhibitor, SB-431542, which preferentially suppresses the activation of the intracellular signal transduction of Smad2 by this receptor $(37,38)$, and sometimes broadly suppresses the TGF- $\beta 1$-induced activation of p38 MAPK, and extracellular signal-regulated kinase (ERK) as opposed to Smad2 (30) was purchased from Calbiochem (La Jolla, CA, USA). Zometa ${ }^{\circledR}$ obtained from Novartis Pharmaceuticals (Tokyo, Japan) was used as ZA in all our experiments. The Cmax of ZA in an adult human body is approximately $1.47 \mu \mathrm{M}$ within $15 \mathrm{~min}$ after its intravenous administration $(4 \mathrm{mg} / 5 \mathrm{ml})$ according to the user instructions provided with Zometa ${ }^{\circledR}$. This is the appropriate amount of ZA for the treatment of cancer bone metastasis $(32,33)$, and is referred in the internal document ZOMU00007 belonging to Novartis Pharmaceuticals.

Cell culture. hGFs were isolated and cultured as described in our previous study (39). Briefly, the cells were isolated from the fresh gingival tissue biopsy samples of 3 volunteers, and were maintained in a Dulbecco's modified Eagle's medium (DMEM) 
supplemented with $10 \%$ fetal bovine serum(FBS) and penicillinstreptomycin (both from Invitrogen, Gaithersburg, MD, USA). Informed consent was obtained from all the volunteers prior to obtaining the samples, and the Ethics Committee of Iwate Medical University approved the research protocol (approval no. 1126). Subsequently, one hGF culture retaining a high proliferative potential among the 3 cultures was used. NIH3T3 mouse embryonic fibroblasts (used as a standard control for the fibroblasts), obtained from RIKEN Cell Bank (Tsukuba, Japan), were cultured with DMEM supplemented with 10\% FBS and penicillin-streptomycin (both from Invitrogen).

Cell viability assay. The status of cell viability was evaluated using an alamarBlue assay (AbD Serotec, Oxon, UK) according to the manufacturer's instructions. This assay reagent includes an indicator that fluoresces and undergoes colorimetric changes when reduced by mitochondrial respiration, which is proportional to the number of living cells. For the viability assay, the cells were seeded in 96-well plates at a density of $2.48 \times 10^{3}$ cells/well and cultured for $48 \mathrm{~h}$ in medium containing $10 \%$ FBS, with or without ZA at the indicated concentrations $(0.0147-147 \mu \mathrm{M})$. Some of the cells were subsequently treated with TGF- $\beta 1(1-5 \mathrm{ng} / \mathrm{ml})$ for $24 \mathrm{~h}$ following treatment with ZA. The medium was replaced with DMEM containing $10 \%$ alamarBlue solution to evaluate the viability of the cells, and the cells were cultured for an additional $4.5 \mathrm{~h}$. The absorbance in each well was measured using an ELISA plate reader (Tosoh Corp., Tokyo, Japan). The data were presented as values of $\mathrm{Abs}_{570}-\mathrm{Abs}_{600}$. Each experiment was repeated 3 times, with 5-wells dedicated for each time point.

$R N A$ isolation and RT-qPCR. Total RNA from the hGFs and NIH3T3 cells was isolated using ISOGEN II reagent (Nippon Gene, Toyama, Japan) according to the manufacturer's instructions. First-strand cDNA was synthesized from total RNA using the PrimeScript RT reagent kit (Takara Bio, Shiga, Japan). PCR was subsequently performed on a Thermal Cycler Dice Real-Time system using SYBR Premix Ex Taq II (both from Takara Bio) with specific oligonucleotide primers (human $\alpha$-SMA forward, 5'-ATACAACATGGCATCATCACCAA-3' and reverse, 5'-GGG CAACACGAAGCTCATTGTA-3'; mouse $\alpha$-SMA forward, 5'-CAGATGTGGATACAGCAAACAGGA-3' and reverse, 5'-GACTTAGAAGCATTTGCGG TGGA-3'; human TGF- $\beta$ type I receptor forward, 5'-GCT GCTCCTCCTCGTGCT-3' and reverse, 5'-TTGTCTTTTGTACAGAGGTGGC-3'; human TGF- $\beta$ type II receptor forward, 5'-CTGCACATCGTCCTG TGG-3' and reverse, 5'-GGAAACTTGACTGCACCGTT-3'; and human glyceraldehyde 3-phosphate dehydrogenase (GAPDH) forward, 5'-GCACCGTCAAGGCTGAGAAC-3' and reverse, 5'-ATGGTGGTGAAGACCCCACT-3'; and mouse GAPDH forward, 5'-TGTGTCCGTCGTGGATCTG-3' and reverse, 5'-TTGCTGTTGAAGTCGCAGGAG-3'). The mRNA expression levels of $\alpha$-SMA, TGF- $\beta$ type I receptor and TGF- $\beta$ type II receptor were normalized to those of GAPDH, and the relative expression levels were presented as the fold increase or decrease relative to the control.

Western blot analysis. The cells were lysed in RIPA buffer [50 mM Tris- $\mathrm{HCl}$ (pH 7.2), $150 \mathrm{mM} \mathrm{NaCl,} \mathrm{1 \%} \mathrm{NP-40,}$ $0.5 \%$ sodium deoxycholate and $0.1 \%$ SDS] or lysis buffer
[20 mM HEPES (pH 7.5), $150 \mathrm{mM} \mathrm{NaCl}, 1 \mathrm{mM}$ EDTA and $1 \%$ Triton $\left.^{\circledR} \mathrm{X}-100\right]$ containing protease and phosphatase inhibitor cocktails (both from Sigma, St. Louis, MO, USA). The protein content of the samples was measured using BCA reagent (Pierce, Rockford, IL, USA). Samples containing equal amounts of protein were separated on $10 \%$ SDS-polyacrylamide gels and transferred onto a polyvinylidenedifluoride membrane (Millipore Corp., Bedford, MA, USA). After being blocked with $1 \%$ BSA or $1 \%$ skim milk in T-TBS $(50 \mathrm{mM}$ Tris- $\mathrm{HCl}$, $\mathrm{pH} 7.2,150 \mathrm{mM} \mathrm{NaCl}$ and $0.05 \%$ Tween-20), the membrane was incubated with primary antibodies including anti- $\alpha$-SMA rabbit polyclonal antibody (1:1,000; ab5694; Abcam, Cambridge, UK), anti-Smad2/3 purified mouse monoclonal antibody $(1: 1,000$; 610842; BD Transduction Laboratories ${ }^{\mathrm{TM}}$, Franklin Lakes, NJ, USA), anti-phospho-Smad2/3 (\#8828), anti-p38 MAPK (\#9212), anti-phospho-p38 MAPK (\#9211), anti-c-Jun N-terminal kinase (JNK; \#9251) and anti-phospho-JNK polyclonal antibodies (\#9252) (1:1,000; all from Cell Signaling Technology,Inc., Beverly, MA, USA) and anti- $\alpha$-tubulin mouse monoclonal antibody (1:25,000; \#3873, Cell Signaling Technology, Inc.) as a loading control for normalization. The proteins of interest were then detected using appropriate horseradish peroxidase-conjugated secondary antibodies (Cell Signaling Technology, Inc.) and an Amersham ECL ${ }^{\mathrm{TM}}$ Prime Western Blotting Detection reagent (GE Healthcare Bio-Sciences, Pittsburgh, PA, USA).

Immunofluorescence analysis of cultured cells. For immunofluorescence analysis of the cultured cells, the hGFs were subcultured on non-coated cover glass slips (Matsunami Glass Ind., Ltd. Kishiwada, Japan) at a density of $2.5 \times 10^{4}$ cells/ glass slip (BD Biosciences, Franklin Lakes, NJ, USA) and maintained in DMEM supplemented with $10 \%$ FBS, with or without ZA $(1.47 \mu \mathrm{M})$ for $48 \mathrm{~h}$. The culture medium was replaced with DMEM without FBS, supplemented with or without TGF- $\beta 1(5 \mathrm{ng} / \mathrm{ml})$. The cells were maintained in this medium for 4 or 5 days, fixed in $4 \%$ paraformaldehyde (Nacalai Tesque, Inc., Kyoto, Japan) for $15 \mathrm{~min}$ and permeabilized with Triton X-100 (Sigma). Following background reduction with normal goat serum, the cells were labeled with anti- $\alpha$-SMA rabbit polyclonal antibody (1:100; ab5694; Abcam), or anti-collagen type I rabbit polyclonal antibody $(1: 100 ; 600-401-103-0.1$; Rockland, Inc., Rockland, ME, USA) at room temperature for $1 \mathrm{~h}$. After being washed with phosphate-buffered saline (PBS) to remove the excess primary antibody, the cells were incubated with Alexa Fluor ${ }^{\circledR}$ 488-conjugated goat anti-rabbit IgG $(1: 1,000$; A-11034; Molecular Probes, Leiden, The Netherlands) and DAPI (1:1,000; KPL, Gaithersburg, MD, USA) for $30 \mathrm{~min}$ at room temperature. After being washed with PBS to remove the excess secondary antibody, the fluorescent signal was detected using an Olympus IX70 fluorescence microscope with the LCPIanFI 20 objective lens (Olympus Co., Tokyo, Japan).

Evaluation of the migratory activities of hGFs and NIH3T3 cells. Cell migration assays were performed using Transwell ${ }^{\circledR}$ membrane cell culture inserts ( $8 \mu \mathrm{m}$ pore size; Corning Inc., Corning, NY, USA) according to the manufacturer's instructions. The hGFs were cultured with or without ZA $(1.47 \mu \mathrm{M})$ in DMEM supplemented with $10 \%$ FBS for $48 \mathrm{~h}$ at a cell density of $6.0 \times 10^{5}$ cells in $10 \mathrm{~cm}$ culture dish. The cells were then placed at a density of $1.0 \times 10^{5}$ cells in the cell culture inserts 
in the each well of a 24-well cell culture plate in DMEM with $0.1 \%$ BSA. The cells were allowed to migrate through the porous membrane that bordered the upper cell culture insert and the lower well of 24-well culture plate which contained DMEM in the presence or absence of TGF- $\beta(5 \mathrm{ng} / \mathrm{ml})$ for $6 \mathrm{~h}$ at $37^{\circ} \mathrm{C}$. TGF- $\beta$ was added to the culture medium in the lower well of 24-well culture plate. In some cases, SB-431542 was added to both the upper and lower culture media. The cells on the upper side of the membrane were wiped, and the membrane was fixed in $4 \%$ paraformaldehyde in PBS. After being washed with PBS, the cells that had migrated onto the underside of the membrane were labeled with DAPI (1:1,000; KPL) and counted. The values were shown as average of those from 3 wells. The evaluation of the migratory activity of the NIH3T3 cells was performed as described above without pre-treatment of the cells with ZA.

Flow cytometry. The hGFs were cultured with or without ZA $(1.47 \mu \mathrm{M})$ in DMEM supplemented with $10 \%$ FBS for $48 \mathrm{~h}$ at a density of $6.0 \times 10^{5}$ cells in a $10-\mathrm{cm}$ culture dish. The cells $\left(1.0 \times 10^{5}\right.$ cells) were suspended in PBS containing $0.5 \%$ FBS and $2 \mathrm{mM}$ EDTA and incubated with anti-TGF- $\beta$ receptor type I (1:100; ab30103) or type II (1:50; ab78419) (both from Abcam) primary antibodies for $1 \mathrm{~h}$ at $4{ }^{\circ} \mathrm{C}$. For the negative control experiments, the cells were incubated with the same protein amount of normal control IgG (sc-2028; Santa Cruz Biotechnology, Inc., Santa Cruz, CA, USA) as each specific antibody. The cells were then incubated with PE-conjugated secondary antibodies (\#732988 for ab31013; \#732970 for ab78419) for $30 \mathrm{~min}$ in the dark. Acquisition was performed using an EPICS XL EXPO 32 ADC system (Beckman Coulter, Fullerton, CA, USA).

Statistical analysis. The data are presented as the mean \pm SD ( $n=3$ or 5 experiments). The data were statistically analyzed using the Student's t-test, and $\mathrm{P}<0.01$ (indicated by an asterisk) was considered significant. The results shown in all experiments are representative of at least 3 separate experiments.

\section{Results}

ZA suppresses the TGF $\beta 1$-induced increase in the viability of $h G F$ s. Treatment with ZA for $48 \mathrm{~h}$ in medium containing $10 \%$ FBS at the concentrations of $0.0147 \mu \mathrm{M}(1 / 100$ of Cmax), $0.147 \mu \mathrm{M}(1 / 10$ of $\mathrm{Cmax})$ and $1.47 \mu \mathrm{M}$ (Cmax) did not affect the viability of the hGFs (Fig. 1A) and the NIH3T3 cells which were used as a standard control for the fibroblasts (Fig. 1B). However, at 10-100-fold higher concentrations (14.7-147 $\mu \mathrm{M})$ than the Cmax, ZA significantly suppressed the viability of the hGFs (35-58\% suppression of the control) and that of the NIH3T3 cells (29-80\% suppression of the control) in a dose-dependent manner. Thus, ZA (Cmax) does not affect the viability of hGFs and normal standard fibroblasts at $48 \mathrm{~h}$ following administration.

In order to elucidate the mechanisms through which ZA affects TGF- $\beta$-induced fibrogenesis by hGFs, the hGFs were pre-treated with ZA (Cmax) for $48 \mathrm{~h}$ and subsequently treated with TGF- $\beta 1$ at the indicated concentrations for the indicated periods of time. Finally, the effect of pre-treatment with ZA (Cmax) on TGF- $\beta$-induced functions in hGFs was investigated using the following experiments:
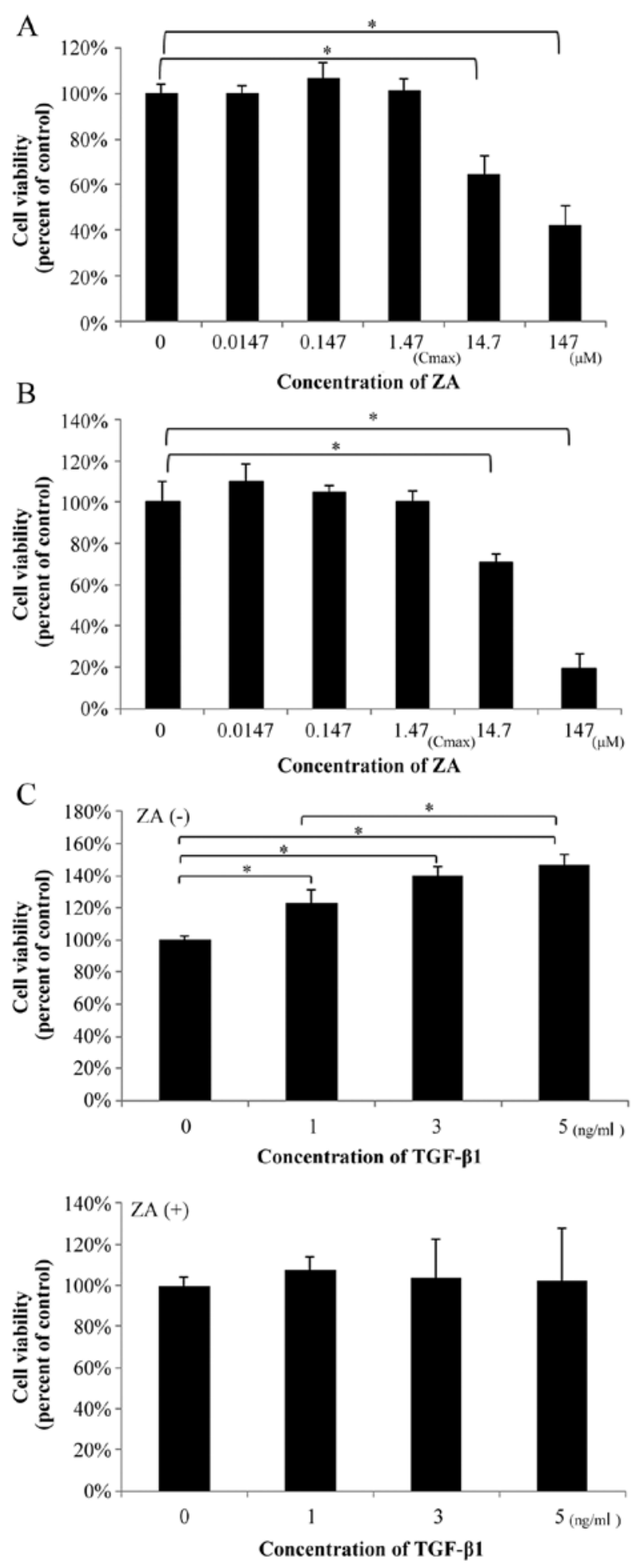

Figure 1. Zoledronic acid (ZA) suppresses the transforming growth factor- $\beta 1$ (TGF- $\beta 1$ )-induced increase in the viability of human gingival fibroblasts (hGFs) at the maximum concentration in serum (Cmax). (A) hGFs and (B) NHI3T3 cells were seeded in 96-well plates at a density of $2.48 \times 10^{3}$ cells/ well and cultured for $48 \mathrm{~h}$ in medium containing $10 \%$ fetal bovine serum(FBS) with or without ZA at the indicated concentrations $(0.0147-147 \mu \mathrm{M})$. The medium was replaced with DMEM containing $10 \%$ alamarBlue solution, and the cells were cultured for an additional $4.5 \mathrm{~h}$. To evaluate the viability of the cells, the absorbance $\left(\mathrm{Abs}_{570}-\mathrm{Abs}_{600}\right)$ in each well was measured using a plate reader. (C) Firstly, hGFs were seeded in 96-well plates at a density of $2.48 \times 10^{3}$ cells/well and cultured for $48 \mathrm{~h}$ in medium containing $10 \%$ FBS with or without ZA (Cmax) (lower, and upper graphs, respectively). The cells were subsequently stimulated with TGF- $\beta 1(1-5 \mathrm{ng} / \mathrm{ml})$ for $24 \mathrm{~h}$. The viability of the hGFs was then measured as described above. The data are presented as the means $\pm \mathrm{SD}(\mathrm{n}=5) .{ }^{*} \mathrm{P}<0.01$ was considered significant. 


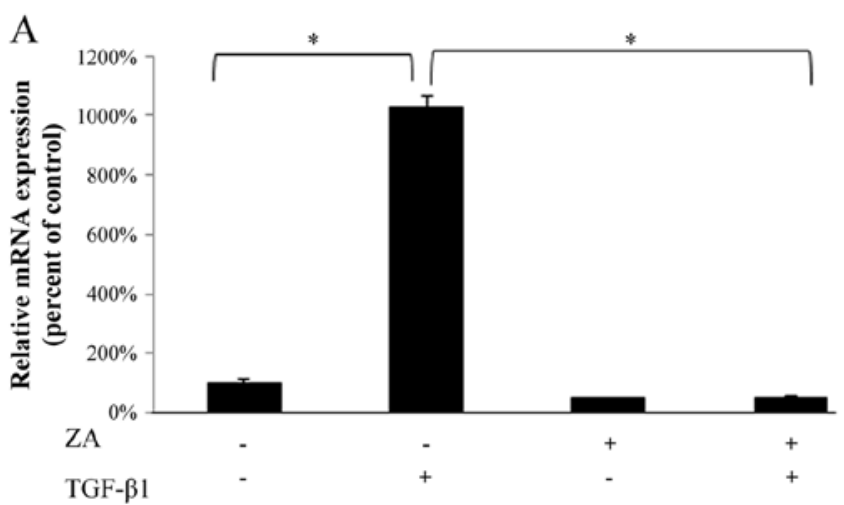

$\mathrm{C}$

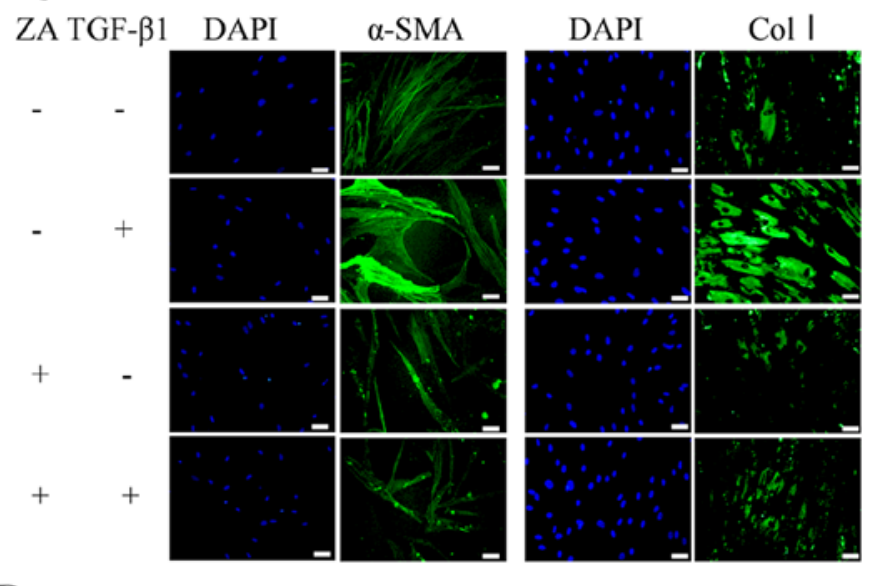

B
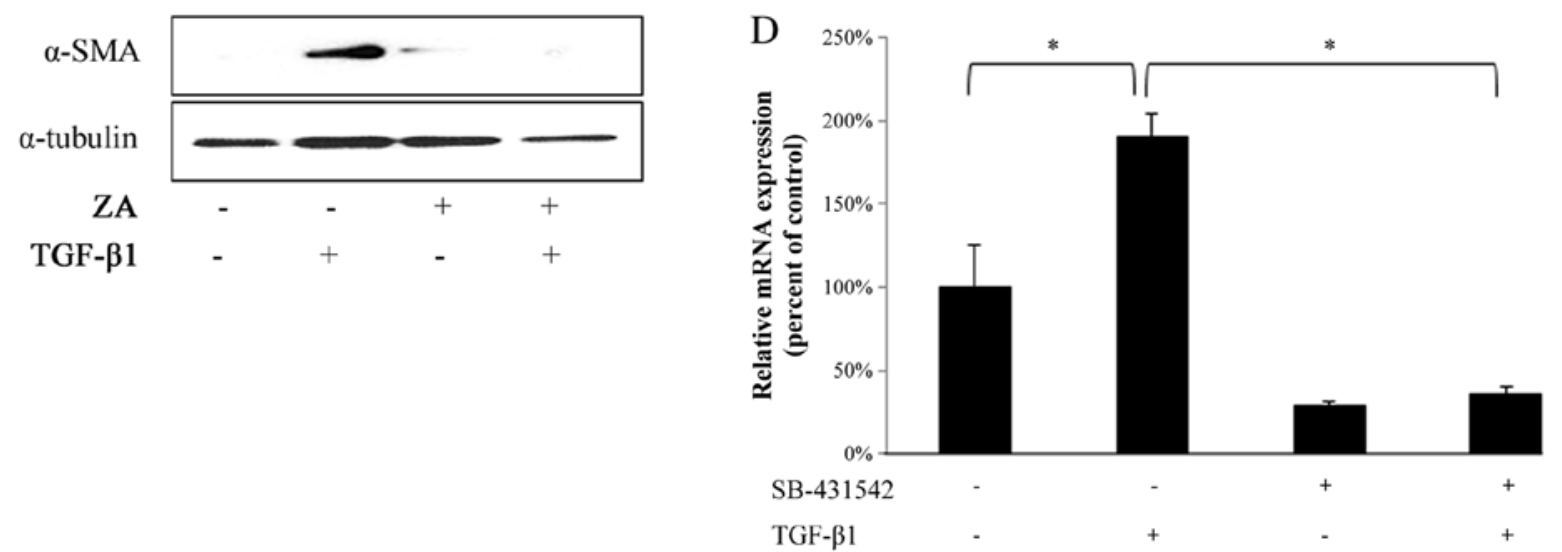

Figure 2. Zoledronic acid (ZA) at the maximum concentration in serum (Cmax) inhibits the transforming growth factor- $\beta$ (TGF- $\beta$ )-induced myofibroblast (MF) differentiation of human gingival fibroblasts (hGFs). (A) hGFs were cultured for $48 \mathrm{~h}$ in growth medium supplemented with $10 \%$ fetal bovine serum (FBS) in the presence or absence of ZA $(1.47 \mu \mathrm{M}$ or Cmax value of an adult human; ZA administered intravenously at $4 \mathrm{mg} / 5 \mathrm{ml})$. The culture medium was replaced with DMEM without FBS supplemented with or without TGF- $\beta 1(5 \mathrm{ng} / \mathrm{ml})$ and maintained for $24 \mathrm{~h}$. The relative expression level of MF marker $\alpha$-smooth muscle actin ( $\alpha$-SMA) was analyzed by RT-qPCR. Data represent the means \pm SD ( $n=3)$. ${ }^{*} \mathrm{P}<0.01$ was considered significant. (B) The status of MF differentiation of hGFs at the protein level was evaluated by western blot analysis with anti- $\alpha$-SMA antibody. The cells were cultured with or without ZA (Cmax) as described in (A), and were subsequently cultured in DMEM without FBS supplemented with or without TGF- $\beta 1$ (5 ng/ml) for 4 days [ $\alpha$-SMA, upper panel; $\alpha$-tubulin (internal control), lower panel]. (C) The cells were first cultured with or without ZA (Cmax) as described in (A), cultured in DMEM without FBS supplemented with or without TGF- $\beta 1(5 \mathrm{ng} / \mathrm{ml})$ for 4 ( $\alpha$-SMA; left panels) or 5 (type I collagen; right panels) days. The cells were then immunostained with anti- $\alpha$-SMA (left panels) (green) and anti-type I collagen (right panels) (green) antibodies. Nuclei were fluorescently counterstained with DAPI (blue). Scale bar, $50 \mu \mathrm{m}$. (D) hGFs were cultured for $48 \mathrm{~h}$ in growth medium supplemented with $10 \% \mathrm{FBS}$, and the medium was replaced with DMEM without FBS supplemented with or without TGF- $\beta 1(5 \mathrm{ng} / \mathrm{ml})$. The cells were maintained for $24 \mathrm{~h}$. Some of the cells were treated with the TGF- $\beta$ receptor inhibitor, SB-431542 (10 $\mu \mathrm{M})$, which was added to the culture medium 30 min prior to stimulation with TGF- $\beta 1$. The relative mRNA expression level of MF marker $\alpha$-SMA was analyzed by RT-qPCR. Data represent the means $\pm \mathrm{SD}(\mathrm{n}=3)$. ${ }^{*} \mathrm{P}<0.01$ was considered significant.

We examined whether ZA (Cmax) affects the viability of hGFs stimulated with TGF- $\beta 1(1-5 \mathrm{ng} / \mathrm{ml})$. As shown in Fig. 1C (upper graph), TGF- $\beta 1(1-5 \mathrm{ng} / \mathrm{ml})$ increased the viability of the hGFs (23-47\% promotion of the control). However, ZA (Cmax) suppressed the TGF $\beta 1$-induced increase in the viability of the hGFs (Fig. 1C, lower graph; compare same TGF- $\beta 1$ concentrations between graphs).

$Z A$ (Cmax) suppresses the TGF- $\beta$-induced MF differentiation of $h G F s$. TGF- $\beta 1(5 \mathrm{ng} / \mathrm{ml})$ significantly upregulated the $\alpha$-SMA mRNA expression level in the hGFs (Fig. 2A, bars 1 and 2 from left). ZA (Cmax) completely suppressed the TGF- $\beta 1$ induced increase in the mRNA expression of $\alpha$-SMA in the hGFs (Fig. 2A, bars 2 and 4 from left). In addition, western blot analysis revealed that ZA (Cmax) clearly suppressed the TGF- $\beta 1$ induced upregulation of $\alpha$-SMA expression at the protein level in the hGFs (Fig. 2B). Immunofluorescence staining also revealed that ZA (Cmax) clearly suppressed the TGF- $\beta 1$-induced upregu- lation of $\alpha$-SMA expression (Fig. $2 \mathrm{C}$, left panels) and type I collagen expression (Fig. 2C, right panels) at the protein level in the hGFs. We confirmed that the TGF- $\beta 1$-induced increase in the mRNA expression of $\alpha$-SMA in the hGFs was significantly inhibited by SB-431542, an inhibitor of TGF- $\beta$ type I receptor (Fig. 2D), indicating that TGF- $\beta 1$ specifically induced the MF differentiation of hGFs through ligand-receptor interaction. Thus, these results indicate that ZA (Cmax) suppresses the TGF- $\beta$-induced MF differentiation of hGFs.

ZA (Cmax) inhibits the TGF- $\beta$-induced migratory activity of $h G F s$. As shown in Fig. 3A and C, the migration of the hGFs through the porous membrane that bordered the upper and lower chambers was significantly enhanced by stimulation with TGF- $\beta 1$ ( $5 \mathrm{ng} / \mathrm{ml})$. However, ZA (Cmax) completely suppressed the TGF- $\beta 1$-induced migratory activity (Fig. $3 \mathrm{~A}$ and B). In addition, we confirmed that the TGF- $\beta$-induced migratory activity was markedly inhibited by SB-431542 (Fig. 3C and D), 

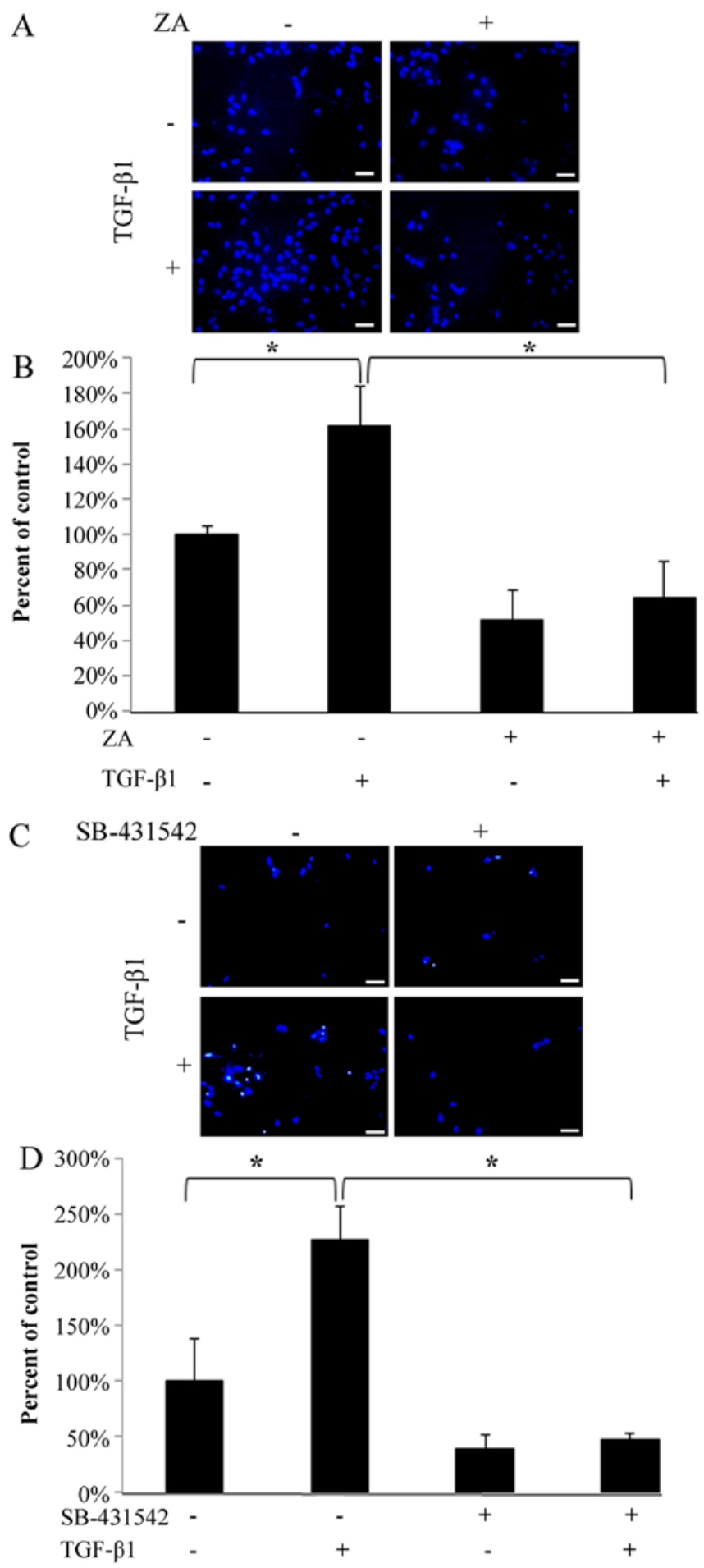

Figure 3.Zoledronic acid (ZA) at the maximum concentration in serum (Cmax) inhibits the transforming growth factor- $\beta$ (TGF- $\beta$ )-induced migratory activity of human gingival fibroblasts (hGFs). Cell migration assays were performed using Transwell ${ }^{\circledast}$ membrane cell culture inserts as described in the Materials and methods. (A and B) hGFs were cultured with or without ZA $(1.47 \mu \mathrm{M})$ for $48 \mathrm{~h}$. The cells were placed in the cell culture inserts in the each well of 24-well cell culture plate. The cells were then allowed to migrate through the porous membrane that bordered the upper cell culture insert and the lower well of 24-well culture plate in the presence or absence of TGF- $\beta 1(5 \mathrm{ng} / \mathrm{ml})$. $(C$ and $D)$ hGFs were placed in the cell culture inserts as described above. The cells were allowed to migrate through the membrane in the presence or absence of TGF- $\beta 1(5 \mathrm{ng} / \mathrm{ml})$. In some cases, SB-431542 was added to both the upper and lower culture media. The cells that had migrated onto the underside of the membrane were labeled with DAPI and visualized using a fluorescent microscope (A and C) and counted (B and D). Data represent the means $\pm \mathrm{SD}(\mathrm{n}=3) .{ }^{*} \mathrm{P}<0.01$ was considered significant. indicating that TGF- $\beta 1$ specifically induced the migration of hGFs through ligand-receptor interaction. These results indicate that ZA (Cmax) inhibits the TGF- $\beta$-induced migratory activity of hGFs.

$Z A$ (Cmax) suppresses the expression of TGF- $\beta$ type I receptor on the surfaces of $h G F s$ and the TGF- $\beta$-induced phosphorylation of Smad2/3 in hGFs. In order to gain insight into the molecular mechanisms underlying the suppressive effects of ZA (Cmax) on TGF- $\beta$-induced fibrogenesis by hGFs, we investigated whether ZA affects the expression of TGF- $\beta$ type I and II receptors on the surface of hGFs. In flow cytometric analysis, hGFs had two peaks in the histogram of TGF- $\beta$ type I receptor-positive cells, that is, 2 groups of hGFs weakly or strongly expressed TGF- $\beta$ type I receptors, respectively (Fig. 4A, upper left panel). Intriguingly, ZA (Cmax) lowered the ratio of the number of cells strongly expressing TGF- $\beta$ type I receptors on their surface against that of total hGFs by 19.6 to $6.4 \%$ (Fig. 4A, upper panels). By contrast, hGFs had only one peak in the histogram of TGF- $\beta$ type II receptor-positive cells (Fig. 4A, lower left panel). ZA (Cmax) did not change the position of the peak in the histogram of TGF- $\beta$ type II receptor-positive cells (Fig. 4A, lower panels). Moreover, RT-qPCR analysis revealed that ZA (Cmax) did not decrease the total amount of both TGF- $\beta$ receptor type (types I and II) expression at the mRNA level (Fig. 4B, upper and lower graphs, respectively), suggesting that ZA (Cmax) suppressed the expression of TGF- $\beta$ type I receptor on the surface of hGFs. In addition, ZA (Cmax) suppressed the TGF- $\beta 1(5 \mathrm{ng} / \mathrm{ml})$-induced phosphorylation of Smad2/3 (Fig. 4C). We confirmed these results by reproducing them in independent experiments.

\section{Discussion}

Wang et al reported that TGF- $\beta 1$ increased the viability of human dermal fibroblasts (40). We found that ZA (Cmax) reduced the TGF- $\beta 1$-induced increase in the viability of hGFs (Fig. 1C). These results suggest that ZA (Cmax) possibly suppresses the TGF- $\beta 1$-induced fibrogenesis in oral gingival tissue. Lu et al reported that TGF- $\beta 1$ promoted the viability of pulmonary artery endothelial cells through Smad2-mediated signal transduction (41). We found that ZA (Cmax) suppressed the TGF- $\beta 1$ ( $5 \mathrm{ng} / \mathrm{ml})$-induced phosphorylation of Smad2/3 (Fig. 4C), implicating that ZA (Cmax) may possibly suppress the TGF- $\beta 1$-induced promotion of the viability of hGFs through suppression of Smad2/3 activities.

Pan et al or Koch et al reported that 5 or $50 \mu \mathrm{M} \mathrm{ZA}$ induced the osteoblastic differentiation of osteoblast precursor cells $(42,43)$. In addition, Chen et al reported that $10 \mu \mathrm{M}$ ZA induced the dendritic cell differentiation of monocytes (44). However, the mechanisms through which ZA (Cmax) affected the differentiation ability of cells derived from the oral cavity remained to be elucidated. In this study, we demonstrated that $1.47 \mu \mathrm{M}$ ZA (Cmax) significantly suppressed the TGF- $\beta 1$-induced MF differentiation of hGFs (Fig. 2A, B, and C). These results strongly suggest that ZA (Cmax) inhibits wound healing in the oral cavity by the attenuation of type I collagen synthesis in MFs differentiated from hGFs following TGF- $\beta 1$ stimulation. In addition, it is generally known that MFs play 
A
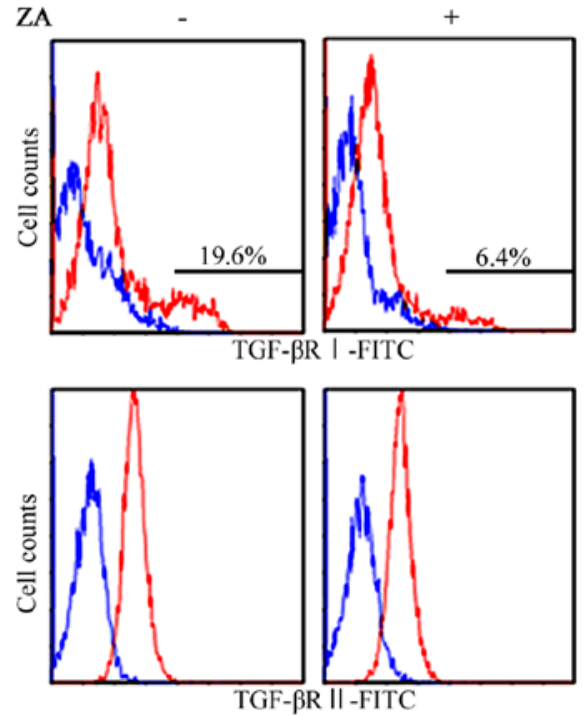

$\mathrm{B}$
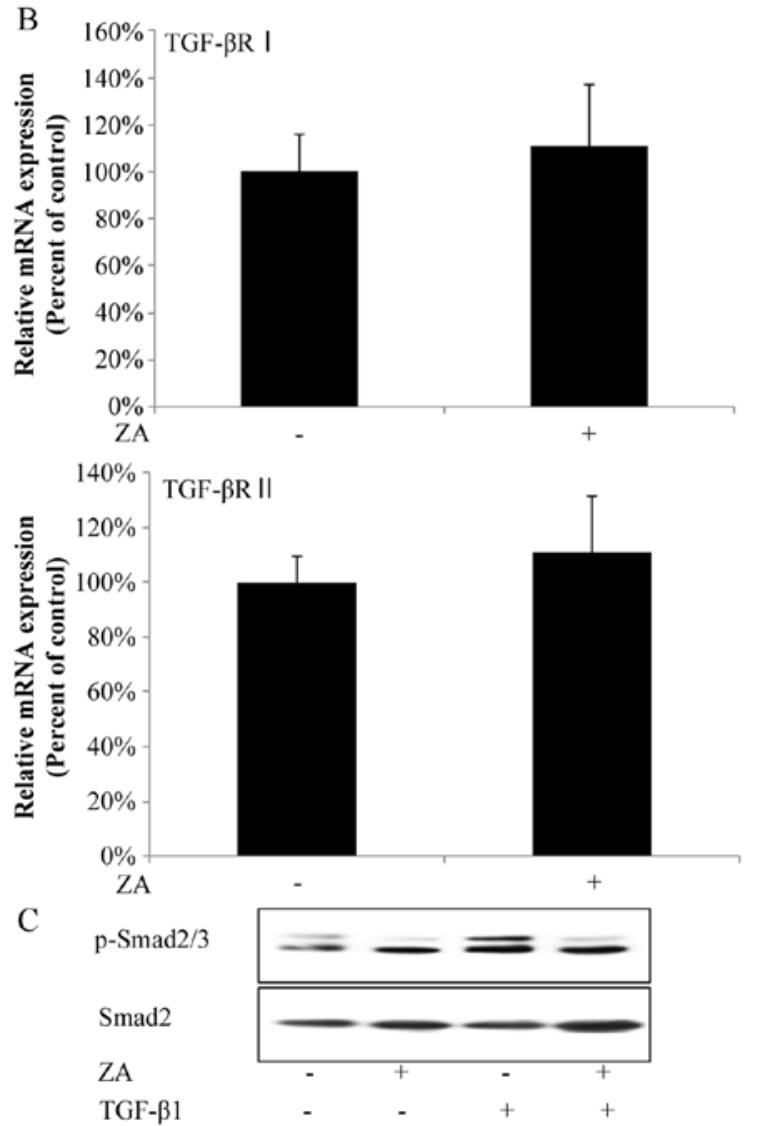

Figure 4.Zoledronic acid (ZA) at the maximum concentration in serum (Cmax) suppresses the expression of transforming growth factor- $\beta$ (TGF- $\beta$ ) type I receptor on the surface of human gingival fibroblasts (hGFs) and the phosphorylation of Smad2/3 in hGFs. (A) hGFs were cultured with or without ZA (Cmax) for $48 \mathrm{~h}$ as described in Fig. 2 at a density of $6.0 \times 10^{5}$ cells in a $10-\mathrm{cm}$ culture dish. The expression levels of TGF- $\beta$ type I (upper panels), and II (lower panels)-receptors on the surface of hGFs were evaluated by flow cytometry using anti-TGF- $\beta$ type I receptor (red) and anti-TGF- $\beta$ type II receptor (red) antibodies or the same amount of normal control IgG (blue). (B) hGFs were cultured for $48 \mathrm{~h}$ in growth medium supplemented with $10 \%$ fetal bovine serum (FBS) in the presence or absence of ZA (Cmax). The relative mRNA expression levels of TGF- $\beta$ type I receptor (upper graph) and TGF- $\beta$ type II receptor (lower graph) were analyzed by RT-qPCR. Data represent the means $\pm \mathrm{SD}(\mathrm{n}=3)$. ${ }^{*} \mathrm{P}<0.01$ was considered significant. (C) hGFs were cultured with or without ZA (Cmax) as described in (A). The cells were subsequently cultured with or without TGF- $\beta 1(5 \mathrm{ng} / \mathrm{ml})$ for $1 \mathrm{~h}$. The phosphorylation of Smad2/3 was evaluated by western blot analyses with antiSmad2/3 and anti-phospho-Smad2/3 antibodies. an important role in generating a contractile force, facilitating wound closure (reviewed in ref. 16), suggesting that ZA (Cmax) also interferes with this process through the suppression of the TGF- $\beta 1$-induced MF differentiation of hGFs. Of note, we found that ZA (Cmax) clearly suppressed the TGF- $\beta 1$-induced phosphorylation of Smad2/3 in hGFs (Fig. 4C). Smad2/3 are known to be key signaling molecules inducing the $\mathrm{MF}$ differentiation of fibroblasts (27). These results suggest that ZA (Cmax) suppressed TGF- $\beta 1$-induced MF differentiation of hGFs through inhibition of Smad2/3 phosphorylation by TGF- $\beta 1$.

Pabst et al reported that ZA at $50 \mu \mathrm{M}$, a much higher concentration than Cmax, significantly decreased the migratory activity of human oral keratinocytes at $72 \mathrm{~h}$ following treatment with ZA (45). However, it remained to be clarified whether ZA (Cmax) affected the migratory activity of various cells derived from the oral cavity, including hGFs. On the other hand, TGF- $\beta$ is known to induce migratory activity in various types of cells, including fibroblastic cells, in a Smad-dependent manner (28-30). In this study, we demonstrated that ZA (Cmax) significantly suppressed the TGF- $\beta 1$-induced migratory activity of hGFs (Fig. 3A and B). Wound healing or mucous re-epithelialization is a complex process involving the proliferation and migration of mesenchymal cells, such as fibroblasts and MFs, which construct granulation tissue for wound closure and then induce mucous re-epithelialization on it (reviewed in ref. 46). As described above, ZA (Cmax) suppressed TGF- $\beta 1$-induced phosphorylation of Smad2/3 (Fig. 4C). These results suggest that ZA (Cmax) suppresses wound closure with granulation tissue in the oral cavity by the inhibition of the TGF- $\beta 1$-induced migration of mesenchymal cells, such as hGFs by suppressing Smad2/3 phosphorylation by TGF- $\beta 1$. On the other hand, Ozdamar et al (47) reported that the phosphorylation of polarity protein Par6 is required for TGF- $\beta 1$-dependent epithelial-to-mesenchymal transition (EMT) in mammary gland ECs and controls the interaction of Par6 with the E3 ubiquitin ligase Smurf1. Smurf1, in turn, targets the guanosine triphosphatase RhoA for degradation, thereby leading to a loss of tight junctions (47). In addition, RhoA is generally known to be a regulator of cell migratory activity in various types of cells by promoting stress fiber assembly and the resultant cell adhesion (48). Intriguingly, serine-to-alanine point mutation [Par6(S345A)] of the TGF- $\beta 1$-induced phosphorylation site in Par6 suppressed the TGF- $\beta 1$-induced EMT in a Smad-independent manner. It remains to be clarified whether ZA (Cmax) suppresses the TGF- $\beta 1$-induced migratory activity of hGFs through affecting Par6/Smurf1/RohA signal transduction pathway in a Smad-independent manner.

Saito et al demonstrated the negative effects of ZA on the re-epithelialization of oral mucosa in a three-dimensional in vitro oral mucosa wound healing model (49). They demonstrated histologically that ZA downregulated the expression of TGF- $\beta$ type I and II receptors and Smad3 phosphorylation in oral keratinocytes. However, they used ZA at $10 \mu \mathrm{M}$, which was a much higher concentration than Cmax, for evaluating the effects on TGF- $\beta 1$-induced signal transduction in human oral keratinocytes. Moreover, they did not elucidate how TGF- $\beta$-induced intracellular signals affect the function of human oral keratinocytes at the cellular and molecular levels. In this study, we demonstrated that ZA (Cmax) lowered the 
ratio of the number of cells strongly expressing TGF- $\beta$ type I receptors on their surface against that of total hGFs, but did not affect the expression status of TGF- $\beta$ type II receptors on hGFs (Fig. 4A). This finding suggests that ZA (Cmax) preferentially suppresses the expression of TGF- $\beta$ type I receptor over that of TGF- $\beta$ type II receptor on the surfaces of hGFs. By contrast, as described above, a high concentration of ZA $(10 \mu \mathrm{M})$ seemed to downregulate the expression of both TGF- $\beta$ receptor types (types I and II). In addition, we found that ZA (Cmax) suppressed the TGF- $\beta 1$-induced phosphorylation of Smad2/3 in hGFs (Fig. 4C), implicating that the suppression of the TGF- $\beta 1$-induced phosphorylation of Smad2/3 in hGFs by ZA (Cmax) may be caused by the inhibition of TGF- $\beta$ type I receptor expression on the surfaces of hGFs. However, it remains to be clarified whether ZA (Cmax) directly suppresses the TGF- $\beta 1$-induced phosphorylation of $\operatorname{Smad} 2 / 3$, or indirectly suppresses that through the inhibition of the TGF- $\beta$ type I receptor expression on the surface of hGFs. On the other hand, Okamoto et al demonstrated that ZA (30-50 $\mu \mathrm{M})$ induced apoptosis and S-phase arrest in mesothelioma by inhibiting the functions of Rab family proteins (50). The Rab family is generally known to control the endosomal trafficking of membrane molecules, such as growth factor receptors (reviewed in ref. 51). It is also generally known that Rab5, activated by a guanine nucleotide exchange factor (GEF), directs TGF- $\beta$-activated receptors into the endocytic pathway that promotes TGF- $\beta$-induced Smad2/3-dependent signals (52). In addition, Kardassis et al suggested that TGF- $\beta$ receptors may be recycled on the cell membrane in a Rab-11-dependent manner following clathrin-dependent internalization of TGF- $\beta$ receptors, which may positively affect the activities of Smad2/3-dependent TGF- $\beta$-induced intracellular signals mediated by these receptors (53). Our laboratory is currently investigating whether ZA (Cmax) suppresses the function of Rab family members that may upregulate the activity of TGF- $\beta 1$-induced Smad2/3-dependent intracellular signals in hGFs at the receptor level, thereby resulting in downregulating TGF- $\beta 1$-induced fibrogenic activity of the cells.

As described above, it has been reported that the TGF- $\beta$ induced activation of p38 MAPK positively regulates migratory activity (31). In fact, TGF- $\beta 1$ upregulated the phosphorylation of p38 MAPK in hGFs; however, ZA (Cmax) did not suppress the TGF- $\beta 1(5 \mathrm{ng} / \mathrm{ml})$-induced phosphorylation of p38 MAPK in hGFs (data not shown), suggesting that p38 MAPK activity is not related to the suppressive effects of ZA (Cmax) on TGF- $\beta 1$-induced fibrogenic activity of hGFs. It is plausible that the suppression of type I receptor expression on the surface of hGFs by ZA (Cmax), as shown in Fig. 4A, may not be sufficient to suppress the TGF- $\beta 1$ induced p38 MAPK phosphorylation. On the other hand, the activation of MAPKs such as JNK and p38 MAPK, but not ERK, is necessary for the progression of the hypoxia-induced MF differentiation of fibroblasts (54). Although, in western blot analysis, the phosphorylation of JNK was not detectable in hGFs before/after TGF- $\beta 1(5 \mathrm{ng} / \mathrm{ml})$ stimulation (data not shown), it remains to be clarified whether JNK affects the TGF- $\beta 1$-induced fibrogenic and migratory activities of hGFs. In addition, the mechanisms through which p38 MAPK affects the TGF- $\beta 1$-induced fibrogenic and migratory activities of hGFs also remains to be clarified.
In conclusion, in the present study, it was suggested that ZA (Cmax) attenuates TGF- $\beta 1$-induced wound closure by inhibiting the formation of granulation tissue by hGFs stimulated with TGF- $\beta 1$ that was derived from inflammatory tissue, possibly through the suppression of Smad2/3 signaling. Our findings partly clarify the molecular mechanisms underlying BRONJ and would benefit research into drug targets at the molecular level for the treatment of this symptom.

\section{Acknowledgements}

This study was supported in part by Grants-in-Aid for Scientific Research (KAKENHI) (grant nos. 24791981 awarded to M.I., 25463053 awarded to N.C., 26462823 awarded to S.K., 22592076 awarded to M.K., 26293426 awarded to T.S., 24593002 awarded to Y.S., and 26670852 awarded to A.I.) from the Ministry of Education, Culture, Sports, Science and Technology of Japan; Grant-in-Aid from the Dental Society of Iwate Medical University; and Grant-in-Aid for Strategic Medical Science Research Centre from the Ministry of Education, Culture, Sports, Science, and Technology of Japan, 2010-2014.

\section{References}

1. Gong L, Altman RB and Klein TE: Bisphosphonates pathway. Pharmacogenet Genomics 21: 50-53, 2011.

2. Boonyapakorn T, Schirmer I, Reichart PA, Sturm I and Massenkeil G: Bisphosphonate-induced osteonecrosis of the jaws: prospective study of 80 patients with multiple myeloma and other malignancies. Oral Oncol 44: 857-869, 2008

3. Fliefel R, Tröltzsch M, Kühnisch J, Ehrenfeld M and Otto S: Treatment strategies and outcomes of bisphosphonate-related osteonecrosis of the jaw (BRONJ) with characterization of patients: a systematic review. Int J Oral Maxillofac Surg 44: 568-585, 2015.

4. Manaka K, Makita N and Iiri T: Erdheim-Chester disease and pituitary involvement: a unique case and the literature. Endocr J 61: 185-194, 2014.

5. Rogers MJ, Crockett JC, Coxon FP and Mönkkönen J: Biochemical and molecular mechanisms of action of bisphosphonates. Bone 49: 34-41, 2011.

6. Vahtsevanos K, Kyrgidis A, Verrou E, Katodritou E, Triaridis S, Andreadis CG, Boukovinas I, Koloutsos GE, Teleioudis Z, Kitikidou K, et al: Longitudinal cohort study of risk factors in cancer patients of bisphosphonate-related osteonecrosis of the jaw. J Clin Oncol 27: 5356-5362, 2009.

7. Marx RE, Sawatari Y, Fortin $M$ and Broumand V: Bisphosphonate-induced exposed bone (osteonecrosis/osteopetrosis) of the jaws: risk factors, recognition, prevention, and treatment. J Oral Maxillofac Surg 63: 1567-1575, 2005.

8. Ruggiero SL, Dodson TB, Assael LA, Landesberg R, Marx RE and Mehrotra B; American Association of Oral and Maxillofacial Surgeons: American Association of Oral and Maxillofacial Surgeons position paper on bisphosphonate-related osteonecrosis of the jaws. J Oral Maxillofac Surg 67 (Suppl 5): 2-12, 2009.

9. Hansen T, Kunkel M, Weber A and James Kirkpatrick C: Osteonecrosis of the jaws in patients treated with bisphosphonates- histomorpholoic analysis in comparison with infected osteoradionecrosis. J Oral Pathol Med 35: 155-160, 2006.

10. Hoefert S, Wierich W, Eufinger H and Krempien B: BP-associated vascular necrosis (AN) of the jaws: histological findings. Bone 38 (suppl 1): 76, 2006.

11. De Ceulaer J, Tacconelli E and Vandecasteele SJ: Actinomyces osteomyelitis in bisphosphonate-related osteonecrosis of the jaw (BRONJ): the missing link? Eur J Clin Microbiol Infect Dis 33: 1873-1880, 2014.

12. Kobayashi Y, Hiraga T, Ueda A, Wang L, Matsumoto-Nakano M, Hata K, Yatani $\mathrm{H}$ and Yoneda T: Zoledronic acid delays wound healing of the tooth extraction socket, inhibits oral epithelial cell migration, and promotes proliferation and adhesion to hydroxyapatite of oral bacteria, without causing osteonecrosis of the jaw, in mice. J Bone Miner Metab 28: 165-175, 2010. 
13. Berti-Couto SA, Vasconcelos AC, Iglesias JE, Figueiredo MA, Salum FG and Cherubini K: Diabetes mellitus and corticotherapy as risk factors for alendronate-related osteonecrosis of the jaws: a study in Wistar rats. Head Neck 36: 84-93, 2014.

14. Molcho S, Peer A, Berg T, Futerman B and Khamaisi M: Diabetes microvascular disease and the risk for bisphosphonate-related osteonecrosis of the jaw: A single center study. J Clin Endocrinol Metab 98: E1807-E1812, 2013.

15. Nisi M, La Ferla F, Karapetsa D, Gennai S, Miccoli M, Baggiani A, Graziani F and Gabriele M: Risk factors influencing BRONJ staging in patients receiving intravenous bisphosphonates: a multivariate analysis. Int J Oral Maxillofac Surg 44: 586-591, 2015.

16. Valluru M, Staton CA, Reed MWR and Brown NJ: Transforming growth factor- $\beta$ and endoglin signaling orchestrate wound healing. Front Physiol 2: 89, 2011.

17. Tipton DA and Dabbous MK: Autocrine transforming growth factor $\beta$ stimulation of extracellular matrix production by fibroblasts from fibrotic human gingiva. J Periodontol 69: 609-619, 1998.

18. Cotrim P, Martelli-Junior H, Graner E, Sauk JJ and Coletta RD: Cyclosporin $\mathrm{A}$ induces proliferation in human gingival fibroblasts via induction of transforming growth factor-beta1. J Periodontol 74: 1625-1633, 2003.

19. Wu MY and Hill CS: TGF- $\beta$ superfamily signaling in embryonic development and homeostasis. Dev Cell 16: 329-343, 2009.

20. Goumans MJ, Liu Z and ten Dijke P: TGF- $\beta$ signaling in vascular biology and dysfunction. Cell Res 19: 116-127, 2009.

21. Heldin CH,Landström M and Moustakas A: Mechanism of TGF- $\beta$ signaling to growth arrest, apoptosis, and epithelial-mesenchymal transition. Curr Opin Cell Biol 21: 166-176, 2009.

22. Liu T and Feng XH: Regulation of TGF- $\beta$ signalling by protein phosphatases. Biochem J 430: 191-198, 2010.

23. Meulmeester E and Ten Dijke P: The dynamic roles of TGF- $\beta$ in cancer. J Pathol 223: 205-218, 2011.

24. Song B, Estrada KD and Lyons KM: Smad signaling in skeletal development and regeneration. Cytokine Growth Factor Rev 20 379-388, 2009

25. Sandbo N and Dulin N: Actin cytoskeleton in myofibroblast differentiation: ultrastructure defining form and driving function. Transl Res 158: 181-196, 2011.

26. Kimura H, Okubo N, Chosa N, Kyakumoto S, Kamo M, Miura H and Ishisaki A: EGF positively regulates the proliferation and migration, and negatively regulates the myofibroblast differentiation of periodontal ligament-derived endothelial progenitor cells through MEK/ERK- and JNK-dependent signals. Cell Physiol Biochem 32: 899-914, 2013.

27. Sobral LM, Montan PF, Zecchin KG, Martelli-Junior H, Vargas PA, Graner E and Coletta RD: Smad7 blocks transforming growth factor- $\beta 1$-induced gingival fibroblast-myofibroblast transition via inhibitory regulation of $\mathrm{Smad} 2$ and connective tissue growth factor. J Periodontol 82: 642-651, 2011.

28. Motizuki M, Isogaya K, Miyake K, Ikushima H, Kubota T, Miyazono K, Saitoh M and Miyazawa K: Oligodendrocyte transcription factor 1 (Olig1) is a Smad cofactor involved in cell motility induced by transforming growth factor- $\beta$. J Biol Chem 288: 18911-18922, 2013

29. Nakano N, Maeyama K, Sakata N, Itoh F, Akatsu R, Nakata M, Katsu Y, Ikeno S, Togawa Y, Vo Nguyen TT, et al: C18 ORF1, a novel negative regulator of transforming grow th factor- $\beta$ signaling. J Biol Chem 289: 12680-12692, 2014.

30. Xiao Y-Q, Liu K, Shen J-F, Xu G-T and Ye W: SB-431542 inhibition of scar formation after filtration surgery and its potential mechanism. Invest Ophthalmol Vis Sci 50: 1698-1706, 2009.

31. Bakin AV, Rinehart C, Tomlinson AK and Arteaga CL: p38 mitogen-activated protein kinase is required for TGFbeta-mediated fibroblastic transdifferentiation and cell migration. J Cell Sci 115: 3193-3206, 2002.

32. Sarrazy V, Billet F, Micallef L, Coulomb B and Desmoulière A: Mechanisms of pathological scarring: role of myofibroblasts and current developments. Wound Repair Regen 19 (Suppl 1): s10-s15, 2011.

33. Van De Water L, Varney S and Tomasek JJ: Mechanoregulation of the myofibroblast in wound contraction, scarring, and fibrosis: Opportunities for new therapeutic intervention. Adv Wound Care (New Rochelle) 2: 122-141, 2013.

34. Hinz B: Formation and function of the myofibroblast during tissue repair. J Invest Dermatol 127: 526-537, 2007.

35. Yoshinami T, Yagi T, Sakai D, Sugimoto N and Imamura F: A case of acquired Fanconi syndrome induced by zoledronic acid. Intern Med 50: 1075-1079, 2011.
36. Kurishima K, Ohara G, Kagohashi K, Takayashiki N, Tamura T, Shiozawa T, Miyazaki K, Kawaguchi M, Satoh $\mathrm{H}$ and Hizawa N: Ossification and increased bone mineral density with zoledronic acid in a patient with lung adenocarcinoma: a case report. Exp Ther Med 8: 1267-1270, 2014

37. DeMaio L, Buckley ST, Krishnaveni MS, Flodby P, Dubourd M, Banfalvi A, Xing Y, Ehrhardt C, Minoo P, Zhou B, et al: Ligand-independent transforming growth factor- $\beta$ type I receptor signalling mediates type I collagen-induced epithelial-mesenchymal transition. J Pathol 226: 633-644, 2012.

38. Xu X, Wan X, Geng J, Li F, Wang C and Dai H: Kinase inhibitors fail to induce mesenchymal-epithelial transition in fibroblasts from fibrotic lung tissue. Int J Mol Med 32: 430-438, 2013.

39. Sawada S, Chosa N, Ishisaki A and Naruishi K: Enhancement of gingival inflammation induced by synergism of IL- $1 \beta$ and IL-6. Biomed Res 34: 31-40, 2013.

40. Wang X, Chu J, Wen CJ, Fu SB, Qian YL, Wo Y, Wang C and Wang DR: Functional characterization of TRAP1-like protein involved in modulating fibrotic processes mediated by TGF- $\beta$ /Smad signaling in hypertrophic scar fibroblasts. Exp Cell Res 332: 202-211, 2015.

41. Lu Q: Transforming growth factor-betal protects against pulmonary artery endothelial cell apoptosis via ALK5. Am J Physiol Lung Cell Mol Physiol 295: L123-L133, 2008.

42. Pan B, To LB, Farrugia AN, Findlay DM, Green J, Gronthos S, Evdokiou A, Lynch K, Atkins GJ and Zannettino AC: The nitrogen-containing bisphosphonate, zoledronic acid, increases mineralisation of human bone-derived cells in vitro. Bone 34 : 112-123, 2004.

43. Koch FP, Merkel C, Al-Nawas B, Smeets R, Ziebart T, Walter C and Wagner W: Zoledronate, ibandronate and clodronate enhance osteoblast differentiation in a dose dependent manner - a quantitative in vitro gene expression analysis of Dlx5, Runx2, OCN MSX1 and MSX2. J Craniomaxillofac Surg 39: 562-569, 2011.

44. Chen YJ, Chao KS, Yang YC, Hsu ML, Lin CP and Chen YY: Zoledronic acid, an aminobisphosphonate, modulates differentiation and maturation of human dendritic cells. Immunopharmacol Immunotoxicol 31: 499-508, 2009.

45. Pabst AM, Ziebart T, Koch FP, Taylor KY, Al-Nawas B and Walter C: The influence of bisphosphonates on viability, migration, and apoptosis of human oral keratinocytes - in vitro study. Clin Oral Investig 16: 87-93, 2012.

46. Tarnawski AS: Cellular and molecular mechanisms of gastrointestinal ulcer healing. Dig Dis Sci 50 (Suppl 1): S24-S33, 2005.

47. Ozdamar B, Bose R, Barrios-Rodiles M, Wang HR, Zhang Y and Wrana JL: Regulation of the polarity protein Par6 by TGFbeta receptors controls epithelial cell plasticity. Science 307: 1603-1609, 2005

48. Tojkander S, Gateva G and Lappalainen P: Actin stress fibers - assembly, dynamics and biological roles. J Cell Sci 125: 1855-1864, 2012.

49. Saito T, Izumi K, Shiomi A, Uenoyama A, Ohnuki H, Kato H, Terada M, Nozawa-Inoue K, Kawano Y, Takagi R and Maeda T: Zoledronic acid impairs re-epithelialization through down-regulation of integrin $\alpha v \beta 6$ and transforming growth factor beta signalling in a three-dimensional in vitro wound healing model. Int J Oral Maxillofac Surg 43: 373-380, 2014.

50. Okamoto S, Jiang Y, Kawamura K, Shingyoji M, Tada Y, Sekine I, Takiguchi Y, Tatsumi K, Kobayashi H, Shimada H, et al: Zoledronic acid induces apoptosis and S-phase arrest in mesothelioma through inhibiting Rab family proteins and topoisomerase II actions. Cell Death Dis 5: e1517, 2014.

51. Aloisi AL and Bucci C: Rab GTPases-cargo direct interactions: fine modulators of intracellular trafficking. Histol Histopathol 28: 839-849, 2013.

52. Hu H, Milstein M, Bliss JM, Thai M, Malhotra G, Huynh LC and Colicelli J: Integration of transforming growth factor beta and RAS signaling silences a RAB5 guanine nucleotide exchange factor and enhances growth factor-directed cell migration. Mol Cell Biol 28: 1573-1583, 2008.

53. Kardassis D, Murphy C, Fotsis T, Moustakas A and Stournaras C: Control of transforming growth factor $\beta$ signal transduction by small GTPases. FEBS J 276: 2947-2965, 2009.

54. Short M, Nemenoff RA, Zawada WM, Stenmark KR and Das M: Hypoxia induces differentiation of pulmonary artery adventitial fibroblasts into myofibroblasts. Am J Physiol Cell Physiol 286: C416-C425, 2004. 